\title{
Bile duct carcinoma associated with congenital biliary dilatation in a 16-year-old female: a case report and literature review
}

\author{
Hideki Izumi ${ }^{1 *}$, Naoki Yazawa', Daisuke Furukawa', Yoshihito Masuoka', Misuzu Yamada', Taro Mashiko', \\ Yohei Kawashima², Masami Ogawa², Yoshiaki Kawaguchi², Tetsuya Mine ${ }^{2}$, Kenichi Hirabayashi ${ }^{3}$ \\ and Toshio Nakagohri ${ }^{1}$
}

\begin{abstract}
We encountered a very rare case of bile duct carcinoma associated with congenital biliary dilatation (CBD) in a 16-year-old female who was admitted to our hospital because of right upper abdominal pain and vomiting. Abdominal computed tomography demonstrated a cystic dilatation of the common bile duct measuring $7 \mathrm{~cm}$ in diameter and two enhanced tumors $4 \mathrm{~cm}$ in diameter located in the inferior bile duct and middle bile duct. Magnetic resonance cholangiopancreatography clearly demonstrated a cystic dilatation of the extrahepatic bile duct (Todani's CBD classification: type 4-A). Endoscopic retrograde cholangiopancreatography also revealed two tumors. Biopsy results of one of the tumors confirmed adenocarcinoma. Excision of the perihilar bile duct and subtotal stomach-preserving pancreaticoduodenectomy with dissection of the major lymph nodes were performed. A postoperative histopathologic examination revealed a well-differentiated tubular adenocarcinoma, which remained within the mucosal layer, and no lymph node metastasis was found. The postoperative course was uneventful, and the patient was discharged 10 days after surgery and has remained disease-free for 21 months.
\end{abstract}

Keywords: Congenital biliary dilatation, Pancreaticobiliary maljunction, Bile duct carcinoma, Pancreaticoduodenectomy

\section{Background}

It is well known that congenital biliary dilatation $(\mathrm{CBD})$ has a significant association with bile duct carcinoma and that CBD merges with pancreaticobiliary maljunction (PBM) in all cases [1]. PBM is a congenital anomaly defined as a junction of the pancreatic and biliary ducts located outside of the duodenal wall that usually forms a markedly long common channel [2, 3]. Some authors have proposed a hyperplasia-dysplasia-carcinoma sequence $[4,5]$. Thus, PBM is thought to be a high risk factor for the development of carcinoma in the biliary tract. Here, we report a rare case of a 16-year-old female with early bile duct carcinoma combined with PBM and CBD.

\footnotetext{
* Correspondence: deehii@is.icc.u-tokai.ac.jp

'Department of Gastrointestinal Surgery, Tokai University School of Medicine,

143 Shimokasuya, Isehara, Kanagawa 259-1193, Japan

Full list of author information is available at the end of the article
}

\section{Case presentation}

A 16-year-old female was admitted to our hospital with a chief complaint of right upper abdominal pain and vomiting. Although our patient was autistic, her condition did not play any role in her present illness. Her body mass index was 18.49 . Her family history included a grandfather treated for colon cancer at an unknown age, but there was no family history of anomalies of the pancreaticobiliary tract system. On physical examination, there was slight tenderness and an abnormal palatable mass in the right upper abdomen. Blood test findings on admission were as follows (Table 1): mild anemia and a longitude increase in hepatobiliary enzymes, amylase, and elastase 1, while levels of carcinoembryonic antigen and cancer antigen 19-9 (CA19-9) were within normal ranges.

Abdominal ultrasonography revealed a cystic dilatation of the extrahepatic bile duct and two protruding tumors in the lumen of the dilated common bile duct (Fig. 1).

\section{Springer}

c 2016 Izumi et al. Open Access This article is distributed under the terms of the Creative Commons Attribution 4.0 International License (http://creativecommons.org/licenses/by/4.0/), which permits unrestricted use, distribution, and reproduction in any medium, provided you give appropriate credit to the original author(s) and the source, provide a link to the Creative Commons license, and indicate if changes were made. 
Table 1 Blood test findings on admission

\begin{tabular}{|c|c|c|}
\hline & Level & Units \\
\hline$\overline{W B C}$ & $4.9 \times 10^{3}$ & $/ \mu l$ \\
\hline $\mathrm{RBC}$ & $4.48 \times 10^{6}$ & $/ \mu l$ \\
\hline $\mathrm{Hb}$ & 10.5 & $\mathrm{~g} / \mathrm{dl}$ \\
\hline $\mathrm{Ht}$ & 33.2 & $\%$ \\
\hline PLT & $37.2 \times 10^{4}$ & $/ \mu l$ \\
\hline BUN & 12 & $\mathrm{mg} / \mathrm{d}$ \\
\hline $\mathrm{Cr}$ & 0.59 & $\mathrm{mg} / \mathrm{d}$ \\
\hline $\mathrm{Na}$ & 141 & $\mathrm{mEq} / \mathrm{l}$ \\
\hline K & 3.9 & $\mathrm{mEq} / \mathrm{l}$ \\
\hline $\mathrm{Cl}$ & 104 & $\mathrm{mEq} / \mathrm{l}$ \\
\hline $\mathrm{Ca}$ & 9.7 & $\mathrm{mg} / \mathrm{d}$ \\
\hline CRP & 0.74 & $\mathrm{mg} / \mathrm{d}$ \\
\hline ALB & 4.7 & $\mathrm{~g} / \mathrm{dl}$ \\
\hline CK & 40 & $U / I$ \\
\hline GOT & 33 & $U / I$ \\
\hline GPT & 66 & $U / I$ \\
\hline ALP & 334 & $\mathrm{U} / \mathrm{I}$ \\
\hline$\gamma$-GTP & 103 & $U / I$ \\
\hline T-Bil & 0.9 & $\mathrm{mg} / \mathrm{d}$ \\
\hline D-Bil & 0.3 & $\mathrm{mg} / \mathrm{d}$ \\
\hline AMY & 138 & $\mathrm{U} / \mathrm{I}$ \\
\hline CEA & 1.2 & $\mathrm{ng} / \mathrm{m}$ \\
\hline CA19-9 & 29.0 & $\mathrm{U} / \mathrm{ml}$ \\
\hline Elastase 1 & 437 & $\mathrm{ng} / \mathrm{dl}$ \\
\hline
\end{tabular}

Doppler ultrasound detected a blood flow signal within the tumor. Abdominal computed tomography (Fig. 2) demonstrated a cyst within the common bile duct measuring $7 \mathrm{~cm}$ in diameter and two enhanced tumors measuring $4 \mathrm{~cm}$ in diameter located in the inferior bile duct and middle bile duct. Magnetic resonance cholangiopancreatography (Fig. 3) clearly demonstrated a cystic dilatation of the extrahepatic bile duct (Todani's CBD classification: type 4-A) [1]. Endoscopic retrograde cholangiopancreatography (Fig. 4) also demonstrated a cystic dilatation of the bile duct as well as the presence of two tumors. Biopsy of one of the tumors confirmed the presence of adenocarcinoma. Amylase, CA19-9, and carcinoembryonic antigen levels in the choledochal cyst were 54,722 IU/l, 230,853 U/ml, and $3.051 \mathrm{ng} / \mathrm{ml}$, respectively.

At laparotomy, the cystic common bile duct was easily found. The wall of the bile duct had no indurations or scaring. Excision of the perihilar bile duct and subtotal stomach-preserving pancreaticoduodenectomy (SSPPD) with dissection of the major lymph nodes were performed. The proximal stump of the choledochus was negative for malignant cells.

The resected specimen demonstrated tumors in the inferior and middle bile ducts (Fig. 5). Immunostaining was positive for CDX2 and negative for MUC1, MUC2, MUC5AC, MUC6, and p53. According to the Union for International Cancer Control (UICC), sixth edition rules, this case was stage 0 (Tis, N0, and M0). A postoperative histopathologic examination revealed a well-differentiated tubular adenocarcinoma, which entirely remained within the mucosal layer, and no lymph node metastasis was found (Fig. 6). The postoperative course was uneventful, and the patient was discharged 10 days after surgery and has remained disease-free for 21 months.

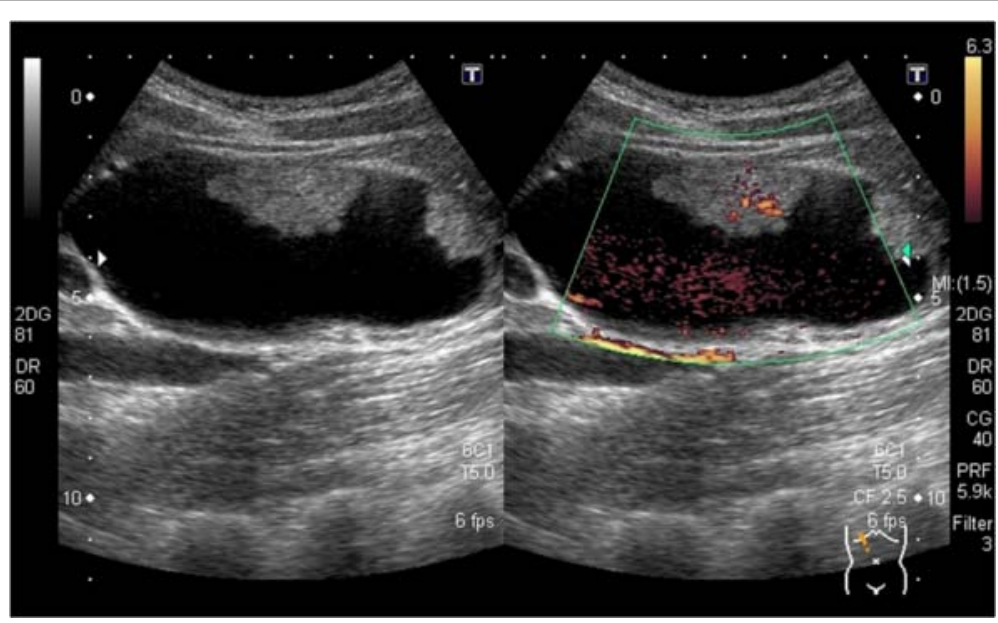

Fig. 1 Abdominal ultrasonography showed two tumors extending into the common bile duct. Doppler ultrasound showed a blood flow signal within the tumor 


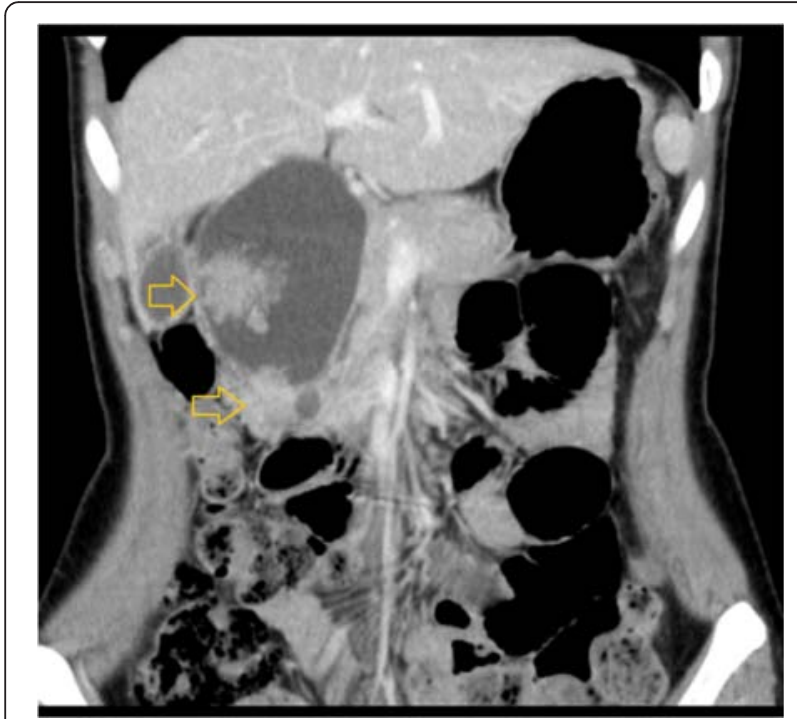

Fig. 2 Abdominal CT showed two enhanced tumors (diameter, $4 \mathrm{~cm}$ ) in the inferior and middle bile duct. Yellow arrows indicate the tumor locations

\section{Discussion}

The disease concept of CBD and classification according to morphological features was first described by AlonsoLej et al. in 1959 [6]. It is well known that CBD merges with $\mathrm{PBM}$ in all cases. PBM is a congenital anomaly

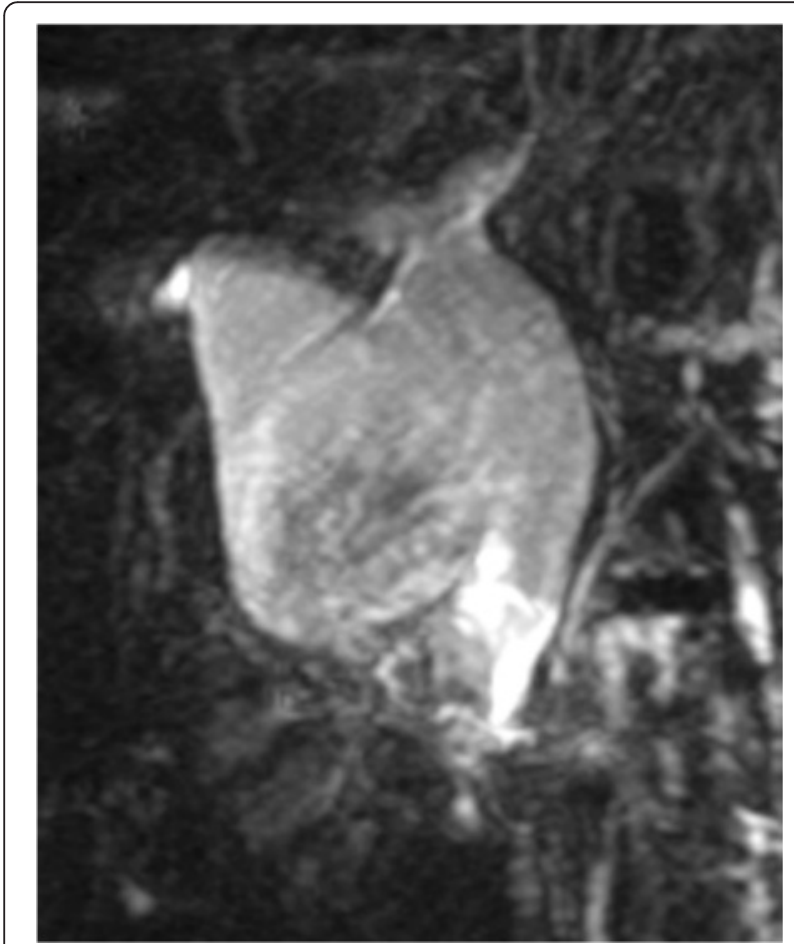

Fig. 3 Magnetic resonance cholangiopancreatography demonstrated a cystic dilatation of the extrahepatic bile duct (Todani's CBD classification: type 4-A)

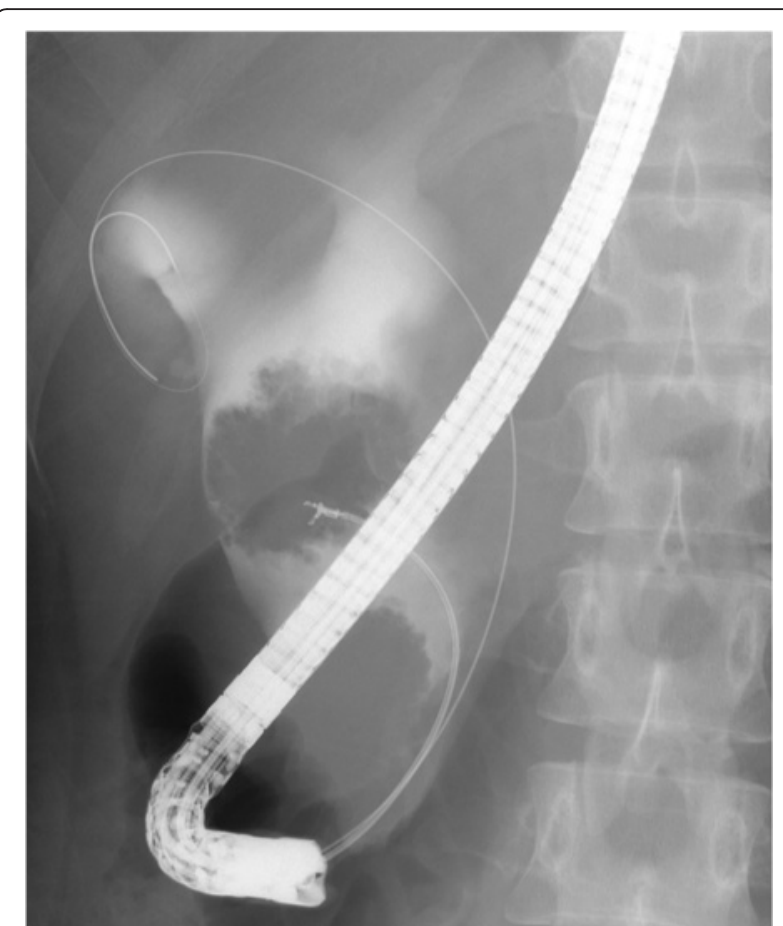

Fig. 4 Endoscopic retrograde cholangiopancreatography showed two tumors, and biopsy of one of the tumors

confirmed adenocarcinoma

defined as a junction of the pancreatic and biliary ducts located outside of the duodenal wall that usually forms a markedly long common channel [2, 3]. As the action of the sphincter of Oddi does not functionally affect this union, two-way regurgitation (biliopancreatic and pancreatobiliary reflux) occurs, resulting in various pathological conditions in the biliary tract and pancreas $[7,8]$. PBM, particularly in Asian patients, is a well-known risk factor for the development of carcinoma in the biliary tract [9]. According to a report by Todani et al. [10], the mean patient age for carcinoma arising in a choledochal cyst is 37 years (range, 15-73 years). Therefore, advanced biliary tract carcinoma in teenage patients is relatively uncommon.

A MEDLINE literature search of English language articles revealed only six cases of biliary tract carcinoma in patients with PBM or CBD younger than 20 years (Table 2) [11-16]. Of these six patients, half were male and the most common PBM subtype was $\mathrm{C}$-P, in which the common bile duct joins the major pancreatic duct. According to the classification of Todani [17], two patients had type 1a disease and two had type 4-A disease. The most common histological type of cancer was adenocarcinoma, and four cases underwent complete tumor resection of the choledochal cyst. 


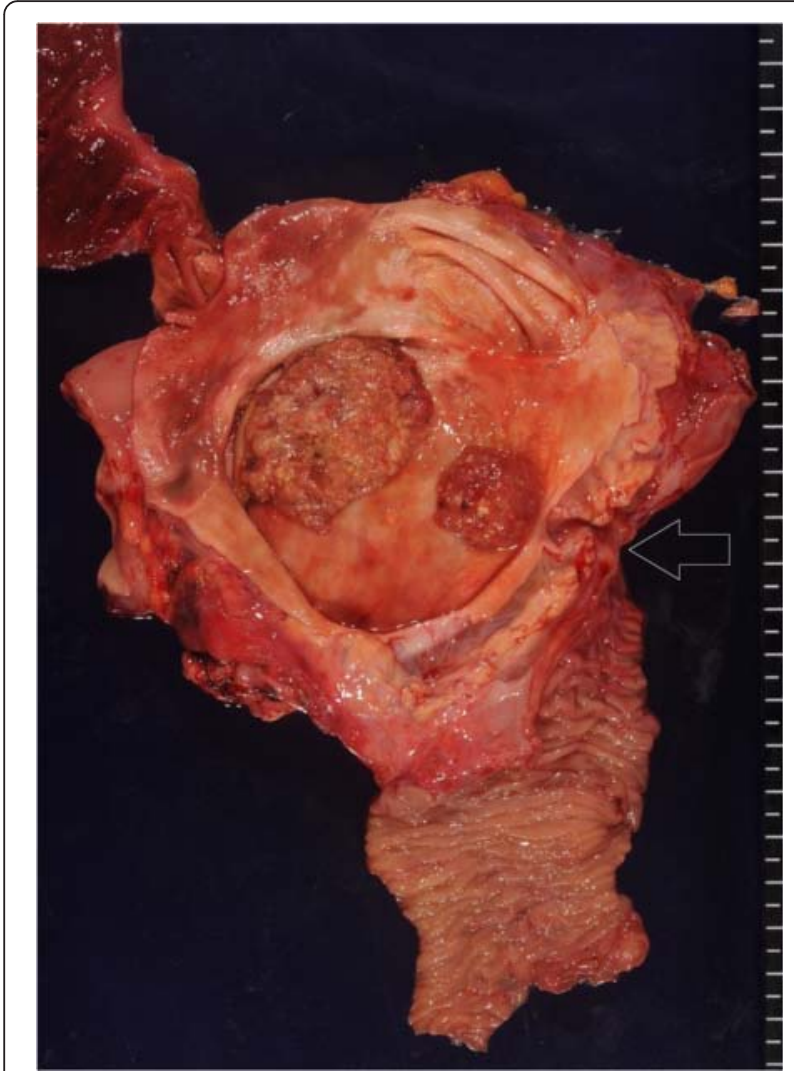

Fig. 5 The resected specimen demonstrated tumors in the inferior and middle bile ducts. Arrow indicates the papilla of Vater
In the present case, the bile amylase level in the common bile duct was $54,722 \mathrm{IU} / \mathrm{l}$, so chronic inflammation leading to malignant change was observed. This high amylase level in the choledochal cyst suggested a free reflux of pancreatic juice into the biliary system that might have caused chronic inflammation in the choledochal cyst [18]. The carcinogenesis of CBD coexisting with PBM is considered to involve the hyperplasia-dysplasiacarcinoma sequence provoked by chronic inflammation resulting from a reflux of pancreatic juices into the biliary tract $[4,5]$. Strong cytotoxic substances are produced when phospholipase A2 in the pancreatic juice mixes with bile, which have been recognized both clinically and experimentally to be injurious to cell membranes. Moreover, the subsequent chronic inflammation provokes high proliferative activity in the mucosal epithelia, finally resulting in CBD in PBM patients [19].

Once a diagnosis of $\mathrm{CBD}$ is made, early radical surgery for CBD combined with thorough intraoperative histopathologic examinations may be necessary, irrespective of the patient's age. A preoperative diagnosis of bile duct carcinoma in CBD is sometimes difficult to establish [16]. In our case, the enhanced huge tumor in the dilated choledochus on CT was an important clue for the diagnosis of malignancy in CBD. The carcinoma spread to the level of the bile duct in the pancreas; therefore, after additional excision of the perihilar bile duct, SSPPD was performed. The surgical procedure should be modified based on the spread of the carcinoma because radical resection appears to be the only chance of cure in such cases.

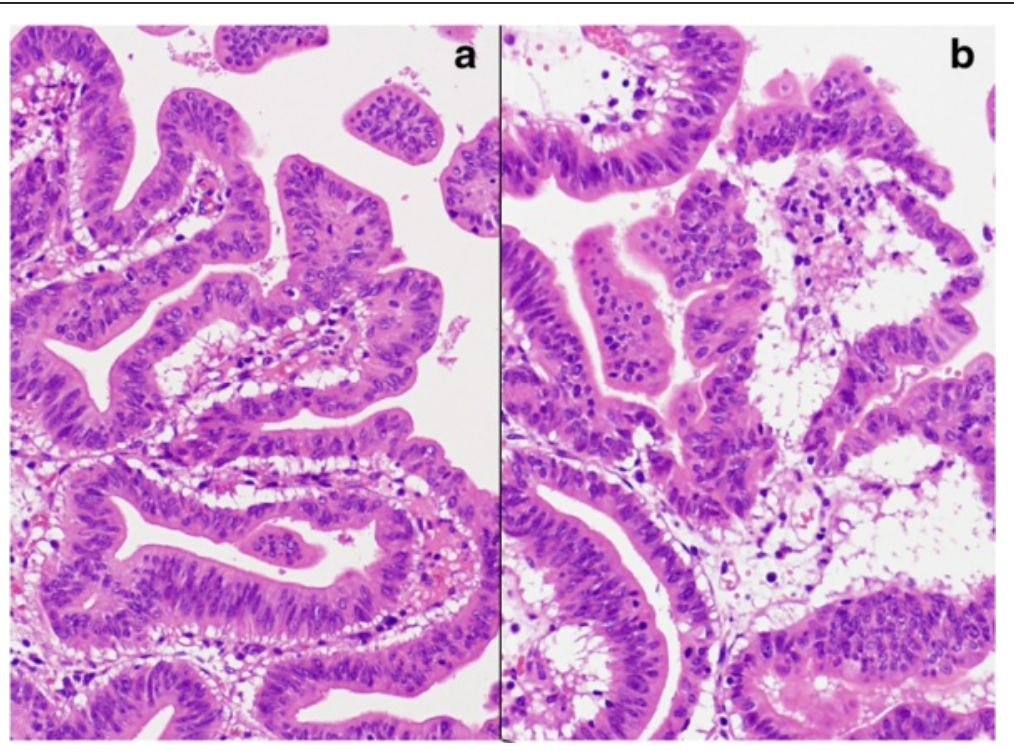

Fig. 6 a, b Pathological examination revealed a well-differentiated tubular adenocarcinoma in the inferior bile duct (a) (hematoxylin and eosin $(H . E ., \times 120)$ and middle bile duct (b) $(H . E ., \times 120)$ 
Table 2 Biliary tract carcinoma in patients with PBM or CBD younger than 20 years

\begin{tabular}{|c|c|c|c|c|c|c|c|c|c|}
\hline No. & Author & Year & Sex & Age & $\begin{array}{l}\text { Classification } \\
\text { of Todani }\end{array}$ & Location of carcinoma & Operation & Histopathology & Outcome \\
\hline 1 & Armanino & 1946 & Male & 17 & Unknown & Liver & Autopsy case & Adenocarcinoma & Dead \\
\hline 2 & Fujiwara & 1976 & Female & 17 & Unknown & $\begin{array}{l}\text { Choledochal duct cyst, } \\
\text { mesenteric lymph node }\end{array}$ & Biopsy of a mesenteric lymph node & Adenocarcinoma & Dead \\
\hline 3 & Iwai & 1990 & Female & 12 & $4-A$ & Intrapancreatic duct & Cyst excision, hepaticojejunostomy & Adenocarcinoma & Dead \\
\hline 4 & Tanaka & 2006 & Male & 11 & $4-A$ & $\begin{array}{l}\text { Cyst wall, common } \\
\text { hepatic duct }\end{array}$ & Cyst excision, PpPD & Adenocarcinoma & Alive \\
\hline 5 & Nakamura & 2008 & Female & 15 & $1 \mathrm{a}$ & Cyst wall, liver metastases & PpPD, partial hepatectomy & Adenocarcinoma & Unknown \\
\hline 6 & Saikusa & 2009 & Male & 3 & $1 \mathrm{a}$ & Cyst wall & Cyst excision, hepaticojejunostomy & Adenocarcinoma & Alive \\
\hline 7 & Our case & 2015 & Female & 16 & $4-A$ & Cyst wall & Cyst excision, SSPPD & Adenocarcinoma & Alive \\
\hline
\end{tabular}

$P P P D$ pylorus-preserving pancreaticoduodenectomy

\section{Conclusions}

We encountered a case of bile duct carcinoma in a 16year-old female with PBM and CBD. The incidence of cancer in young people with CBD is very low; however, CBD can become cancerous after a long period of time has elapsed. Therefore, at the time of diagnosis of CBD, a preoperative inspection for bile duct carcinoma may be necessary.

\section{Consent}

Written informed consent was obtained from the patient's parents for publication of this case report and all accompanying images. A copy of the written consent form is available for review from the Editor-in-Chief of this journal.

\section{Abbreviations}

CA19-9: Cancer antigen 19-9; CBD: Congenital biliary dilatation; $\mathrm{CT}$ : Computed tomography; PBM: Pancreaticobiliary maljunction; SSPPD: Subtotal stomach-preserving pancreaticoduodenectomy.

\section{Competing interests}

The authors declare that they have no competing interests.

\section{Authors' contributions}

NY, DF, YM, MY, TM, and TN carried out the surgery and postoperative management. $\mathrm{YK}, \mathrm{MO}, \mathrm{YK}$, and TM carried out the medical diagnosis. $\mathrm{KH}$ carried out the pathological diagnosis. All authors read and approved the final manuscript.

\section{Acknowledgements}

The authors would like to thank Enago for the English language review.

\section{Author details}

${ }^{1}$ Department of Gastrointestinal Surgery, Tokai University School of Medicine, 143 Shimokasuya, Isehara, Kanagawa 259-1193, Japan. ${ }^{2}$ Department of Internal Medicine, Tokai University School of Medicine, 143 Shimokasuya, Isehara, Kanagawa 259-1193, Japan. ³Department of Pathology, Tokai University School of Medicine, 143 Shimokasuya, Isehara, Kanagawa 259-1193, Japan.

Received: 11 October 2015 Accepted: 18 January 2016

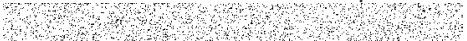

\section{References}

1. Todani T, Watanabe Y, Narusue M, Tabuchi K, Okajima K. Congenital bile duct cysts: classification, operative procedures, and review of thirty-seven cases including cancer arising from choledochal cyst. Am J Surg. 1977;134:263-9.

2. Kimura K, Ohto M, Saisho H, Unozawa T, Tsuchiya Y, Morita M. Association of gallbladder carcinoma and anomalous pancreaticobiliary ductal union. Gastroenterology. 1985;89:1258-65.

3. Kamisawa T, Egawa N, Nakajima H, Tsuruta K, Okamoto A, Matsukawa M. Origin of the long common channel based on pancreatographic findings in pancreaticobiliary maljunction. Dig Liv Dis. 2005;37:363-7.

4. Shimada K, Yanagisawa J, Nakayama F. Increased lysophosphatidylcholine and pancreatic enzyme content in bile of patients with anomalous pancreaticobiliary ductal junction. Hepatology. 1991;13:438-44.

5. Tokiwa K, Iwai N. Early mucosal changes of the gallbladder in patients with anomalous arrangement of the pancreaticobiliary duct. Gastroenterology. 1996:110:1614-8.

6. Alonso-Lej F, Rever WB, Pessagno DJ. Congenital choledochal cyst, with a report of 2, and an analysis of 94, cases. Int Abstr Surg. 1959;108:1-30.

7. Komi N, Tamura T, Miyoshi Y, Kunitomo K, Udaka H, Takehara H. Nationwide survey of cases of choledochal cyst. Analysis of coexistent anomalies, complications and surgical treatment in 645 cases. Surg Gastroenterol. 1984;3:69-73.

8. Kamisawa T, Matsukawa M, Amemiya K, Tu Y, Egawa N, Okamoto A, et al. Pancreatitis associated with pancreaticobiliary maljunction. Hepatogastroenterology. 2003;50:1665-8.

9. Reveille RM, Van Stiegmann G, Everson GT. Increased secondary bile acids in a choledochal cyst. Possible role in biliary metaplasia and carcinoma. Gastroenterology. 1990;99:525-7.

10. Todani T, Tabuchi K, Watanabe $Y$, Kobayashi T. Carcinoma arising in the wall of congenital bile duct cysts. Cancer. 1979;44:1134-41.

11. Armanino LP. Idiopathic dilatation of the common bile duct with coexistent primary hepatic carcinoma; report of a case. Ann Inter Med. 1946;24:714-26.

12. Fujiwara $Y$, Ohizumi T, Kakizaki G, Ishidate T. A case of congenital choledochal cyst associated with carcinoma. J Pediatr Surg. 1976;11(4):587-8.

13. Iwai $N$, Deguchi $E$, Yanagihara J, Iwai M, Matsuo $H$, Todo $S$, et al. Cancer arising in a choledochal cyst in a 12-year-old girl. J Pediatr Surg. 1990;25: 1261-3.

14. Tanaka S, Kubota M, Yagi M, Okuyama N, Ohtaki M, Yamazaki S, et al. An 11-year-old male patient demonstrating cholangiocarcinoma associated with congenital biliary dilatation. J Pediatr Surg. 2006;41:e15-9.

15. Nakamura $\mathrm{H}$, Katayose $\mathrm{Y}$, Rikiyama $\mathrm{T}$, Onogawa $\mathrm{T}$, Yamamoto $\mathrm{K}$, Yoshida $\mathrm{H}$, et al. Advanced bile duct carcinoma in a 15-year-old patient with pancreaticobiliary maljunction and congenital biliary cystic disease. J Hepatobiliary Pancreat Surg. 2008;15:554-9.

16. Saikusa N, Naito S, linuma Y, Ohtani T, Yokoyama N, Nitta K. Invasive cholangiocarcinoma identified in congenital biliary dilatation in a 3-year-old boy. J Pediatr Surg. 2009;44:2202-5. 
17. Todani T, Watanabe Y, Toki A, Morotomi Y. Classification of congenital biliary cystic disease: special reference to type Ic and IVA cysts with primary ductal stricture. J Hepatobiliary Pancreat Surg. 2003;10:340-4.

18. Kamisawa T, Okamoto A. Biliopancreatic and pancreatobiliary refluxes in cases with and without pancreaticobiliary maljunction: diagnosis and clinical implications. Digestion. 2006;73:228-36.

19. Tsuchida A, Itoi T. Carcinogenesis and chemoprevention of biliary tract cancer in pancreaticobiliary maljunction. World J Gastrointest Oncol. 2010;2:130-5.

\section{Submit your manuscript to a SpringerOpen ${ }^{\circ}$ journal and benefit from:}

- Convenient online submission

- Rigorous peer review

- Immediate publication on acceptance

- Open access: articles freely available online

- High visibility within the field

- Retaining the copyright to your article

Submit your next manuscript at $>$ springeropen.com 